\title{
La entonación del español hablado por italianos
}

\author{
Empar DEVÍs HERRÁIZ \\ Universitat de València \\ Departamento de Filologia Española \\ empardevis@gmail.com
}

Recibido: mayo 2010

Aceptado: marzo 2011

\section{RESUMEN}

En este trabajo describimos los rasgos melódicos de un grupo de italianos hablantes de español, con el método de análisis melódico del habla puesto a punto en el laboratorio de fonética de la Universidad de Barcelona. Nuestro objetivo es caracterizar su interlengua, con el fin de implementar la enseñanza de la pronunciación en este contexto.

Hemos utilizado un corpus de 254 enunciados, de los cuales hemos seleccionado para el análisis 99 (49 interrogativas y 50 neutras).

Los enunciados fueron producidos por 12 informantes, todos ellos italianos y hablantes avanzados de español.

Los resultados del análisis nos permiten proponer los rasgos melódicos de la entonación prelingüística de los italianos que hablan español, así como los patrones melódicos más comunes de la entonación interrogativa y de la entonación neutra y suspendida.

Palabras clave: entonación, acento extranjero, pronunciación.

\section{RÉSUMÉ}

\section{L'intonation de l'espagnol parlé par des Italiens}

Dans ce travail nous décrivons les traits mélodiques d'un groupe d'italiens qui parlent l'espagnol, avec la méthode d'analyse mélodique de la parole mise à un point dans le laboratoire de phonétique de l'Université de Barcelone. Notre objectif est de caractériser leur interlangue, afin de mettre en application l'enseignement de la prononciation dans ce contexte. Nous avons utilisé un corpus de 254 énoncés, desquels nous avons sélectionné pour l'analyse 99 (49 interrogatives et 50 neutres).

Les énoncés ont été produits par 12 informateurs, tous italiens et parlant un espagnol avancé. Les résultats de l'analyse nous permettent de proposer les traits mélodiques de l'intonation prélinguistique des Italiens qui parlent espagnol, ainsi que les patrons mélodiques les plus communs de l'intonation interrogative et de l'intonation neutre et suspendue.

Mots-clés : intonation, accent étranger, prononciation.

\section{The intonation of Spanish spoken by Italians}

\begin{abstract}
In this work we describe the melodic features of a group of speaking italians of spanish, with the method of melodic analysis of the speech designed in the laboratory of phonetics of the University of Barcelona. Our aim is to characterize your interlanguage, in order to implement the education of the pronunciation in this context.
\end{abstract}


We have used a corpus of 254 sentences, of which we have selected for the analysis 99 (49 interrogative ones and 50 neutral ones).

The terms of reference were produced by 12 informants, all of them Italian and speaking outposts of spanish.

The results of the analysis allow us to propose the melodic features of the intonation prelingüística of the Italians who speak Spanish, as well as the most common melodies of the interrogative intonation and of the neutral and suspended intonation.

Keywords: intonation, foreign accent, pronunciation.

SUMARIO: 1. Introducción. 2. Metodología. 3. Corpus. 3.1 Informantes. 3.2 Grabaciones y estilo de entrevista. 3.3 Extracción de los enunciados. 4. Entonación del español hablado por italianos. 4.1 Entonación lingüística. 4.2 Entonación prelingüística. 5. Conclusiones. Referencias bibliográficas.

\section{INTRODUCCIÓN}

En este trabajo nos proponemos presentar la caracterización melódica de la interlengua de los italianos que han aprendido español como lengua extranjera (E/LE).

Llamamos interlengua a los estadios de desarrollo en la competencia comunicativa de un hablante, particularmente de un hablante extranjero (v. Selinker, 1972).

A las características fónicas de la interlengua podemos llamarlas, en su conjunto, interlengua fónica, y, estás están fuertemente condicionadas por el "factor melódico". Básicamente, la interlengua fónica de un hablante extranjero depende de su entonación prelingüística ${ }^{1}$.

De los tres niveles de análisis de la entonación ${ }^{2}$, el factor clave para la comprensión o la incomprensión del discurso del otro, tiene que ver con la entonación prelingüistica, la organización fónica del habla: el "factor melódico" de la pronunciación.

La manifestación más evidente de este "factor melódico" es el acento extranjero: la organización del discurso en un idioma según los rasgos de la entonación prelingüística de otro idioma, especialmente la melodía que estructura las unidades del discurso. Es decir, hablar un idioma con la entonación de otro.

El mismo fenómeno ocurre también entre las diversas variedades de un mismo idioma: lo que conocemos como acento dialectal. Cada comunidad de hablantes de un idioma que ha desarrollado algún tipo de identidad lingüística diferencial (por motivos geográficos, por ejemplo) lo que ha hecho es, básicamente, especializarse en un "estilo" de melodía, en un perfil melódico cuyo juego entre los acentos principales del enunciado determina cómo será su primer pico tonal, cómo declinará la melodía a

${ }^{1}$ Se trata del primer nivel de entonación descrito por Cantero (2002). Comprende los fenómenos del acento, el ritmo y la melodía, que funcionan solidariamente como elementos fónicos coestructuradores del discurso, al margen de cualquier otra dimensión significativa.

${ }^{2}$ Prelingüística, lingüística y paralingüística, según Cantero (2002). 
lo largo del enunciado, y sobre todo cómo se establecerá la última inflexión tonal del mismo.

Estos rasgos melódicos (primer pico tonal, declinación de la melodía, inflexión final) junto con otros como el campo tonal de la enunciación, la prominencia de los segmentos tónicos o átonos de la melodía, su eventual desdoblamiento (o inflexiones internas), etc., determinan las características de los contornos de entonación, independientemente de su rendimiento fonológico. Así, podemos tener una melodía inequívocamente interrogativa (cuyo rasgo fonológico sea /+ interrogativo/), desde un punto de vista fonológico idéntica a otra melodía interrogativa que, sin embargo, suena totalmente distinta: piénsese en cómo la misma pregunta absoluta puede sonar en español peninsular, en español de México o en español de La Plata. Las variedades dialectales de un idioma están codificadas, esencialmente (sin desdeñar otros factores, como el léxico o la morfología), en término melódicos, de entonación prelingüística.

Del mismo modo, el discurso de un hablante extranjero (independientemente de su competencia léxico-gramatical, incluso de su competencia pragmática) está codificado, esencialmente, en términos melódicos. Un italiano que habla español puede ser fácilmente reconocible como extranjero (como italiano) no tanto por el léxico utilizado, o por sus soluciones morfológicas, sino sobre todo por su entonación, y en concreto (como veremos más adelante) por el perfil melódico de sus enunciados, por los rasgos melódicos de su discurso.

El análisis melódico de la interlengua, por tanto, nos permitirá una caracterización pormenorizada de los rasgos más relevantes de la pronunciación de nuestros hablantes extranjeros, como premisa para una enseñanza de la pronunciación más eficaz.

Paralelamente, el análisis de la interlengua nos permitirá entender mejor los procesos de desarrollo de la adquisición fónica en lenguas extranjeras, así como los elementos de transferencia que actúan de una lengua a otra.

Nuestro objetivo es conocer las características reales de los hablantes italianos que usan el español como lengua extranjera, a partir del análisis melódico de su interlengua, teniendo en cuenta que el factor clave en la interlengua fónica de un hablante de LE es el factor melódico, con la finalidad de afrontar la enseñanza de la pronunciación desde la descripción de la realidad y no desde la norma. En concreto nos proponemos dar respuesta a los siguientes objetivos:

1. en primer lugar, especificar la entonación lingüística de los italianos al hablar en castellano, sobre la base de las curvas melódicas con las que emiten enunciados declarativos e interrogativos;

2. en segundo lugar, describir la entonación prelingüística de dichos informantes con un nivel avanzado de español conversando en castellano;

3. en tercer lugar, detallar el proceso de interferencia y caracterizar la interlengua entonativa de los italianos que hablan español.

4. y, en cuarto lugar, ofrecer una serie de propuestas didácticas para la enseñanza de la entonación en el aula. 


\section{METODOLOGÍA}

Para el análisis del corpus utilizamos el método de Análisis melódico del habla que presenta F.J. Cantero (2002) en su libro Teoría y Análisis de la entonación. El cual permite:

- Segmentar la curva entonativa en segmentos tonales;

- Analizar la entonación independiente de otros niveles de análisis lingüístico;

- Analizar todos los fenómenos tonales del habla incluidos en la melodía (acento, ritmo y entonación).

El método comprende dos fases:

Fase acústica (descriptiva):

- Extracción de la F0 del enunciado;

- Determinación de los valores de F0 vocálicos. Se identifican las vocales y se anota su valor medio;

- La sucesión de valores vocálicos genera una curva melódica esencial que elimina los valores irrelevantes;

- Y, en último lugar, cada patrón melódico obtenido en $\mathrm{Hz}$ se estandariza en porcentajes para construir una melodía independiente de las características del hablante.

Fase perceptiva (experimental):

- Se sintetiza la melodía resultante: por ejemplo, aquellos rasgos melódicos cuya relevancia queremos comprobar;

- Se realiza un experimento perceptivo que permita validar la melodía sintetizada y/o falsar la hipótesis melódica.

\section{CORPUS}

Para realizar el análisis melódico de la interlengua de los italianos que hablan español hemos partido del corpus de grabaciones que se empleó en Devís (2008). El corpus analiza exclusivamente el habla espontánea lo cual nos permite obtener una imagen real de la interlengua fónica de los informantes.

\subsection{Informantes}

Para nuestro estudio, seleccionamos una serie de hablantes nativos italianos, con nivel avanzado de español, con los cuales se contacta para conseguir un corpus de 
habla que nos permita comprobar las transferencias de entonación entre el italiano y el español.

Recogemos las grabaciones de 12 informantes (todos ellos venecianos, profesores de español en la universidad y residentes en Venecia y Madrid). Mostramos dos tablas con información sociolingiística, la primera relativa a los hombres y la segunda a las mujeres.

\begin{tabular}{|c|c|c|c|c|}
\hline H & EDAD & ESTUDIOS & PROCEDENCIA & RESIDENCIA \\
\hline 1 & 43 & Doctor & Venecia & Madrid \\
\hline 2 & 45 & Doctor & Venecia & Madrid \\
\hline 3 & 44 & Doctor & Venecia & Madrid \\
\hline 4 & 44 & Doctor & Venecia & Bolonia \\
\hline 5 & 36 & Licenciado & Venecia & Venecia \\
\hline
\end{tabular}

\begin{tabular}{|c|c|c|c|c|}
\hline M & EDAD & ESTUDIOS & PROCEDENCIA & RESIDENCIA \\
\hline 1 & 34 & Licenciada & Venecia & Madrid \\
\hline 2 & 59 & Doctora & Venecia & Madrid \\
\hline 3 & 43 & Licenciada & Venecia & Bolonia \\
\hline 4 & 38 & Doctora & Venecia & Venecia \\
\hline 5 & 51 & Licenciada & Venecia & Venecia \\
\hline 6 & 39 & Doctora & Venecia & Venecia \\
\hline 7 & 60 & Licenciada & Venecia & Venecia \\
\hline
\end{tabular}

El requisito para que la persona pueda ser un posible informante es que sea profesor de español para garantizar su nivel avanzado.

Los informantes fueron localizados a través de contactos personales y las citas se concertaron en un ambiente relajado para el informante. El lugar más adecuado para esta actividad fue la casa de éste último, ya que la persona en su propio hogar está más cómoda y distendida para empezar cualquier conversación.

\subsection{Grabaciones y estilo de entrevista}

Para las grabaciones se utilizó una grabadora analógica. Las cintas que empleamos para grabar las conversaciones son de la marca SONY, modelo DAT (Digital Audio Tape).

Las entrevistas se realizaron en un estilo neutral, en parejas que se conocían entre ellas. Cuando no se pudo concertar una cita en pareja entonces la autora hizo uso de su intervención. El sujeto podía expresarse sobre cualquier tema seleccionado por él mismo. La finalidad de esta metodología es que el informante converse con naturalidad y espontaneidad. Para la obtención de las interrogativas, en cambio, se les pedía que, de manera alternada, pensaran en una película o en un personaje famoso y mediante preguntas intentaran adivinar. 


\subsection{Extracción de los enunciados}

La digitalización del corpus se realizó con el programa informático Multi-speech, modelo $3700^{3}$. Cada enunciado, así, se convierte en un archivo, cuyo nombre es un código de identificación.

Para la extracción de la curva de F0, de los enunciados previamente segmentados se utilizó, en cambio, el programa Praat de análisis acústico y síntesis de la señal.

El corpus total consta de un total de 15 horas de grabación en conversación espontánea (mitad en italiano y mitad en castellano), de los cuales hemos seleccionado para este trabajo 99 enunciados en castellano de los 12 informantes (49 interrogativas y 50 neutras).

Después de la selección de los enunciados relevantes se procede a su transcripción ${ }^{4}$.

\section{ENTONACIÓN DEL ESPAÑOL HABLADO POR ITALIANOS}

A continuación presentamos algunos de los ejemplos del corpus analizado distinguiendo entre entonación lingüística ${ }^{5}$ y entonación prelingüística.

\subsection{Entonación lingüística}

En español, Cantero (2002) distingue ocho tonemas (resultantes de la combinación de los rasgos fonológicos: / \pm interrogativo, \pm suspendido, \pm enfático/), que comúnmente llama entonación neutra, interrogativa, suspendida o enfática, y cuyos patrones melódicos constituyen las melodías típicas del idima.

3 Para mayor información sobre las características aplicativas consultar la página www.kayelemetrics.com

${ }^{4}$ Ver apendice 1.

${ }^{5}$ Se trata del segundo nivel de entonación descrito por Cantero (2002). Comprende los rasgos melódicos cuyo rendimiento fonológico permite caracterizar y distinguir las unidades funcionales de la entonación, sus "signos lingüísticos". 


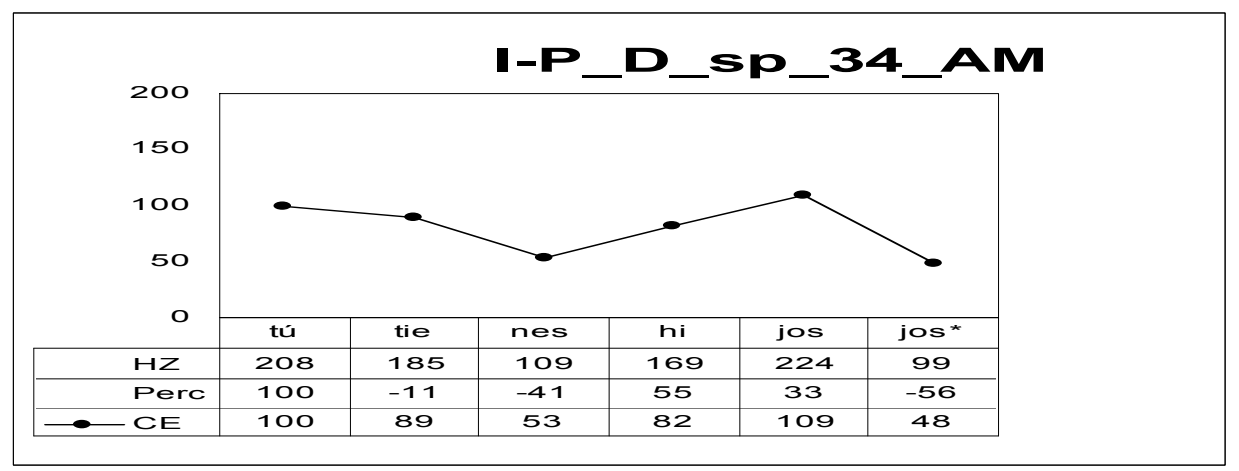

Figura 1. Corresponde a la melodía estandarizada interrogativa: “¿Tú tienes hijos?”

En la figura 1 podemos observar una inflexión final circunfleja ascendentedescendente (similar a un tipo de interrogativa en español: el patrón IV. V. Cantero \& Font, 2007).

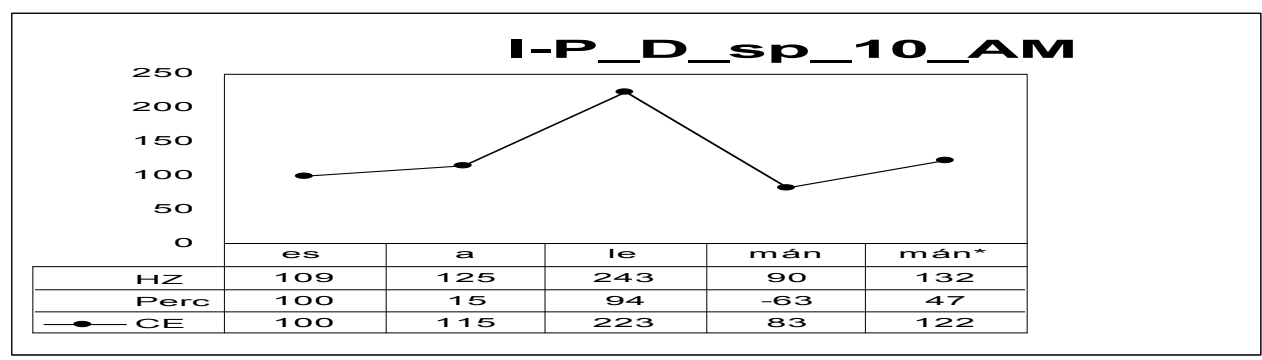

Figura 2. Corresponde a la melodía estandarizada interrogativa: ¿Es alemán?”

En la figura 2 observamos una inflexión final circunfleja descendente-ascendente (inexistente en español como interrogativa).

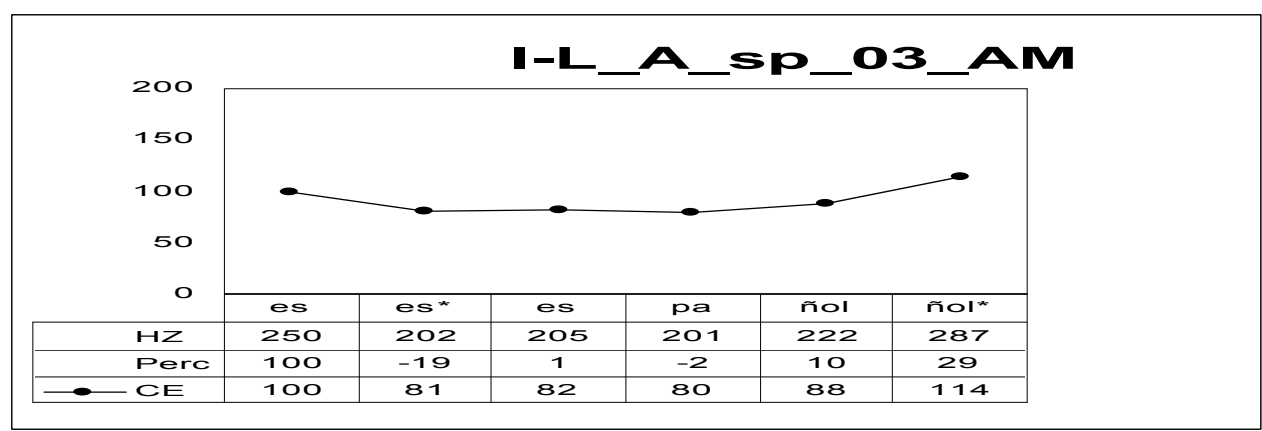

Figura 3. Corresponde a la melodía estandarizada interrogativa: “¿Es español?” 
En la figura 3 observamos una inflexión final ascendente, con un 39\% de ascenso (que en español correspondería a un enunciado suspendido).

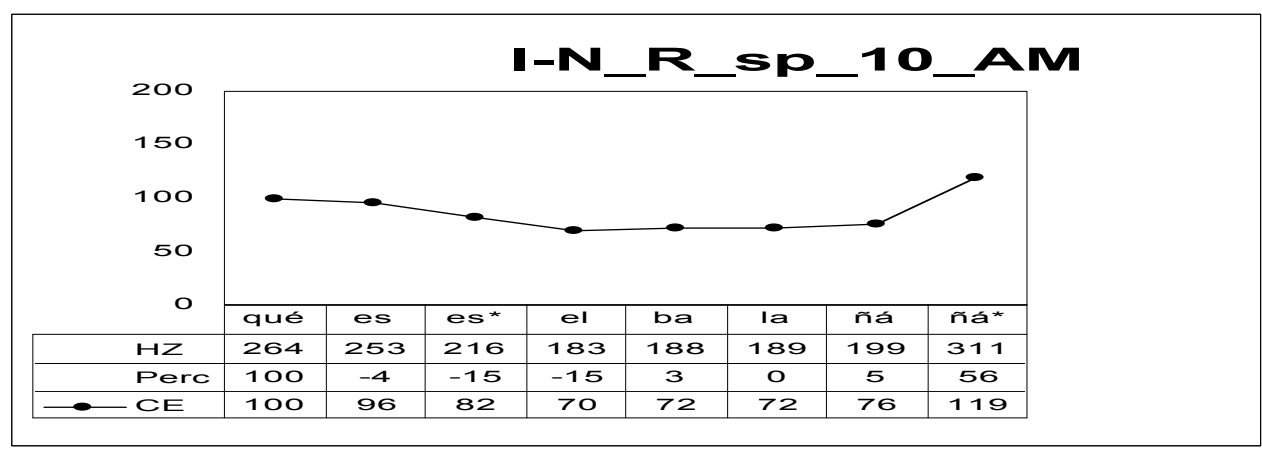

Figura 4. Corresponde a la melodía estandarizada interrogativa: “¿Qué es el balañá?”

En la figura 4 observamos una inflexión final ascendente, con un $61 \%$ de ascenso (que en español tal vez podría reconocerse como interrogativa).

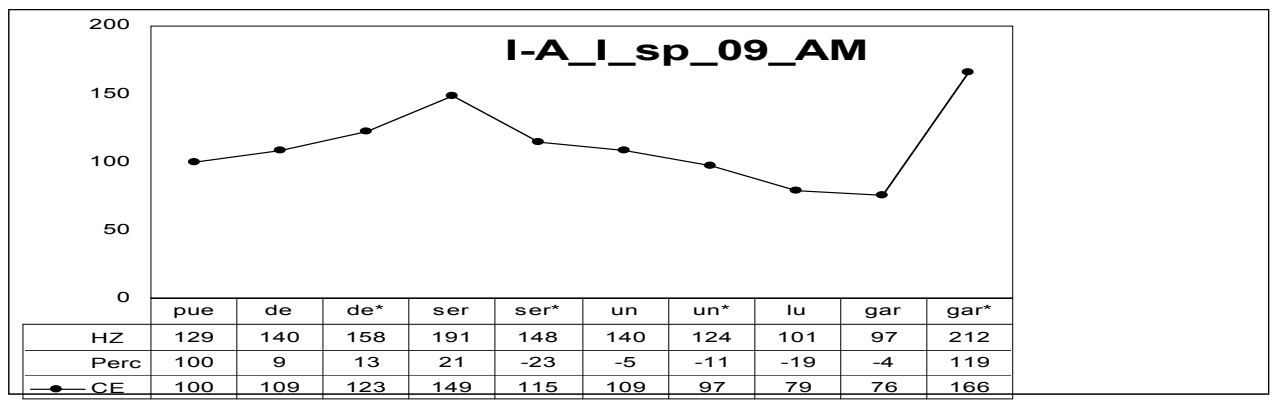

Figura 5. Corresponde a la melodía estandarizada interrogativa: “¿Puede ser un lugar?”

En la figura 5 observamos una inflexión final ascendente, con un $118 \%$ de ascenso (como la interrogativa absoluta en español, aunque en el corpus Cantero, 2002, corresponde a preguntas con énfasis). 


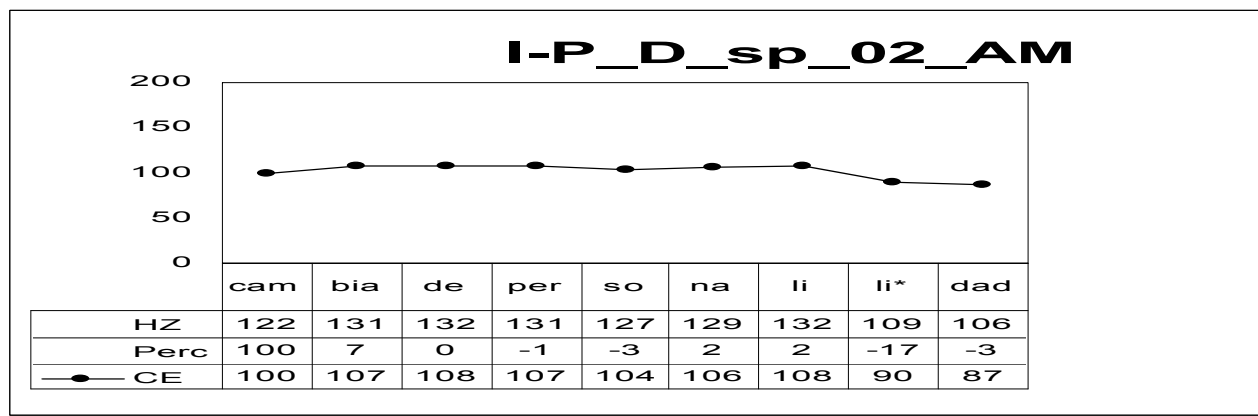

Figura 6. Corresponde a la melodía estandarizada interrogativa: “¿Cambia de personalidad?”

En la figura 6 observamos una interrogativa descendente con un $20 \%$ de descenso.

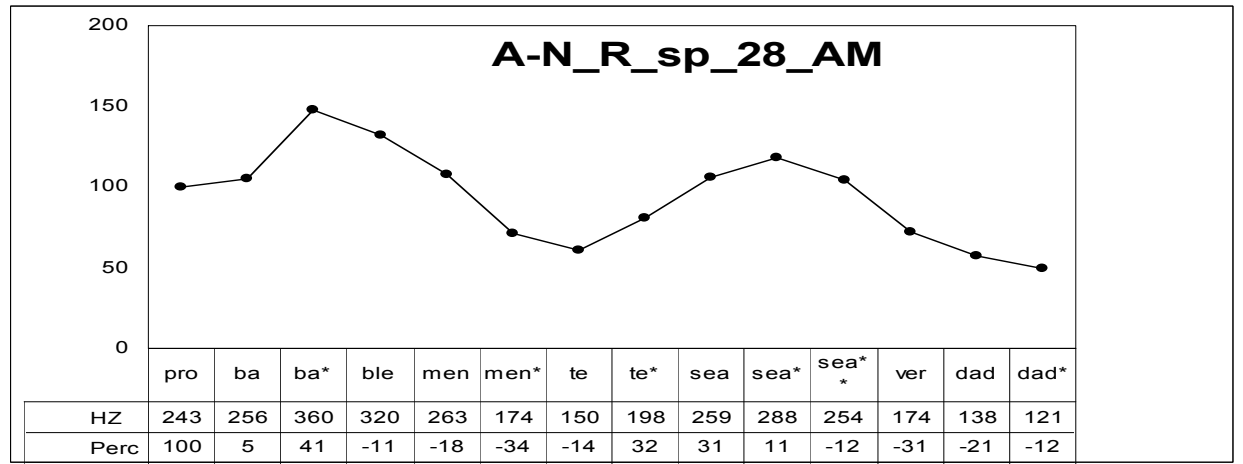

Figura 7. Corresponde a la melodía estandarizada neutra: "Probablemente sea verdad"

En la figura 7 observamos un enunciado neutro con énfasis de palabra en la inflexión final.

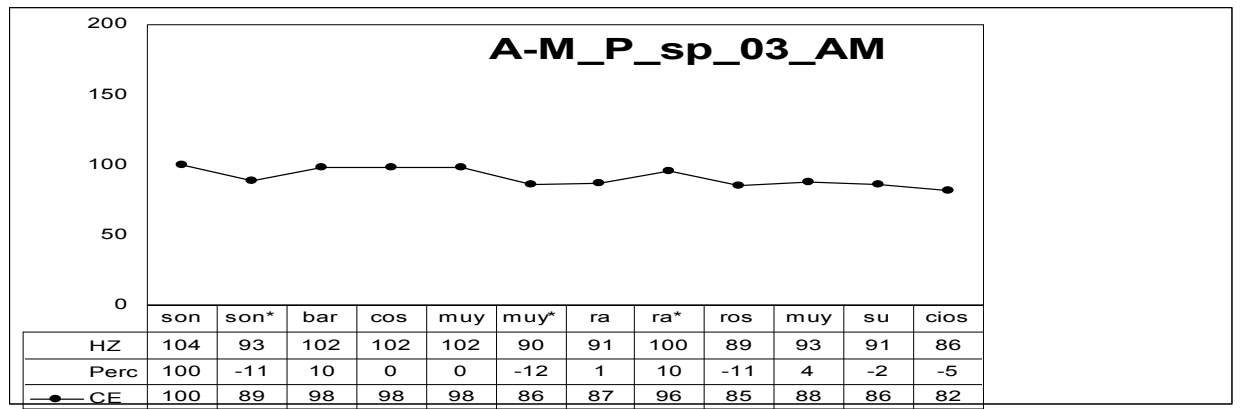

Figura 8. Corresponde a la melodía estandarizada neutra: "Son barcos muy raros muy sucios" 
En la figura 8 observamos una inflexión final plana, similar a la entonación suspendida del español.

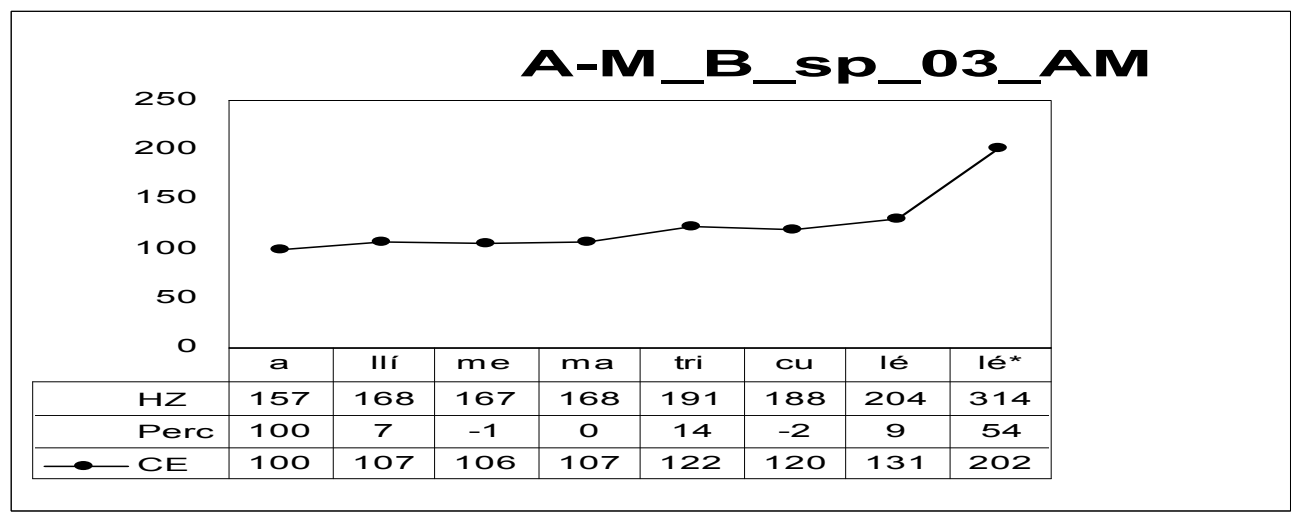

Figura 9. Corresponde a la melodía estandarizada suspensiva: "Allí me matriculé"

En la figura 9 observamos una suspendida con un ascenso final del 54\%.

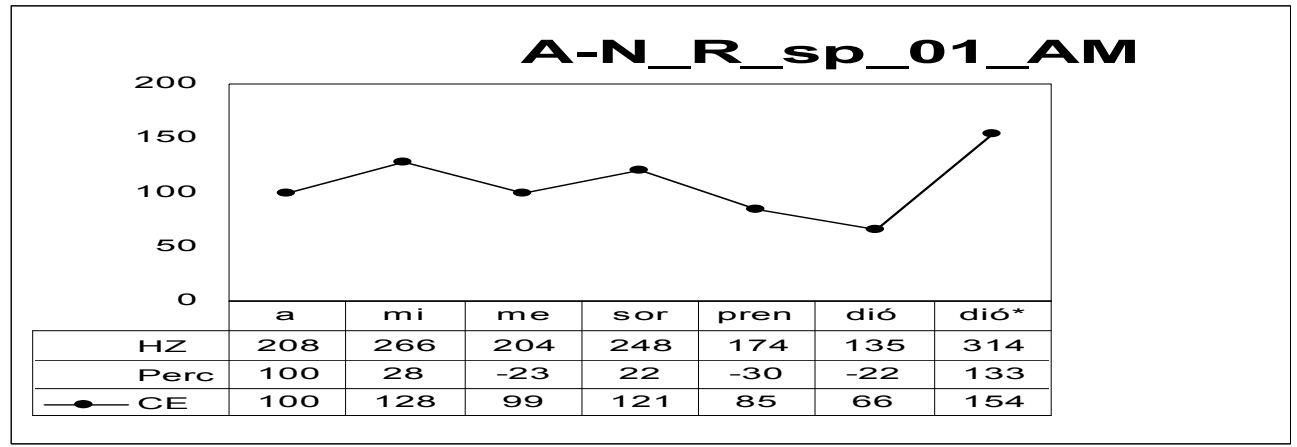

Figura 10. Corresponde a la melodía estandarizada suspensiva: "A mi me sorprendió"

En la figura 10 observamos una suspendida con un ascenso final del 132\% que sería reconocida en español como interrogativa. 


\subsection{Entonación prelingüística}

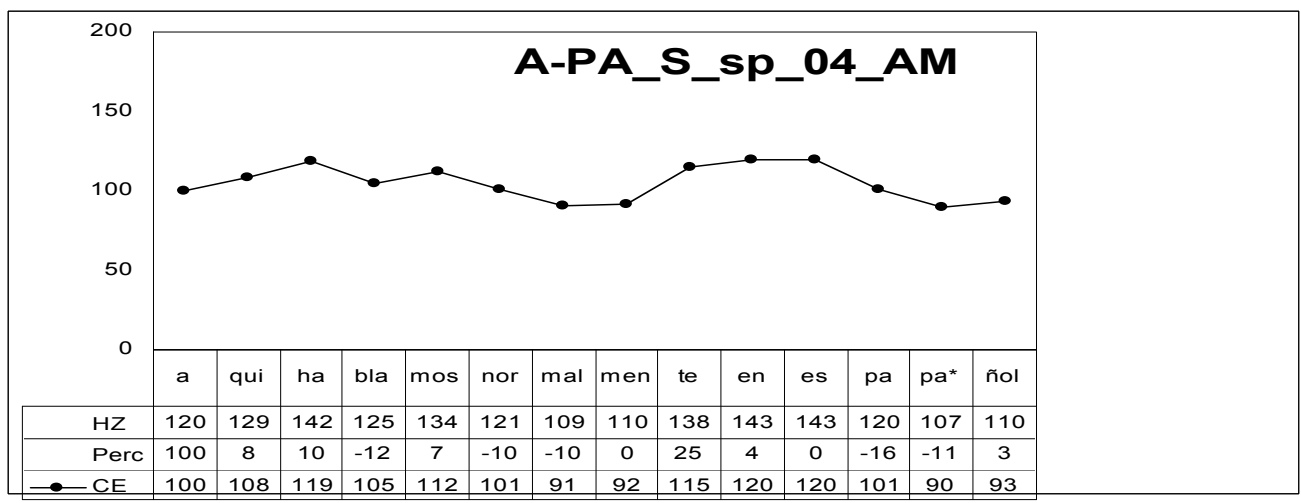

Figura 11. Corresponde a la melodía estandarizada neutra: "Aquí hablamos normalmente en español"

En la figura 11 observamos un fenómeno muy recurrente que caracteriza del perfil melódico de nuestros informantes, y es la fuerte tendencia a enfatizar las vocales pretónicas finales. Véase la sílaba "es" de "español" donde la inflexión final comienza en la pretónica.

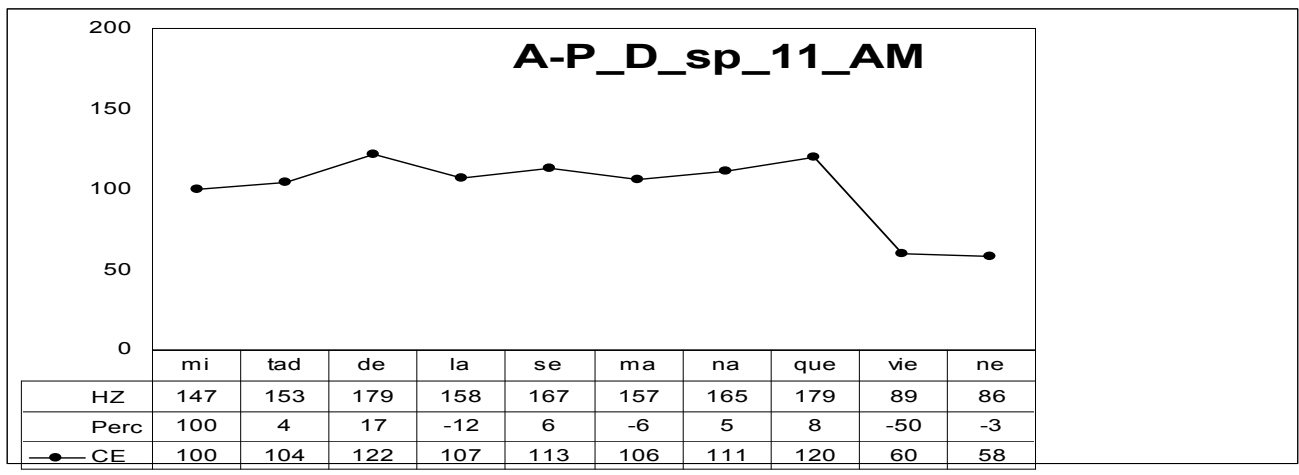

Figura 12. Corresponde a la melodía estandarizada neutra: "Mitad de la semana que viene"

En la figura 12 observamos el mismo fenómeno. La vocal enfatizada "que" es la átona anterior a la última tónica. 


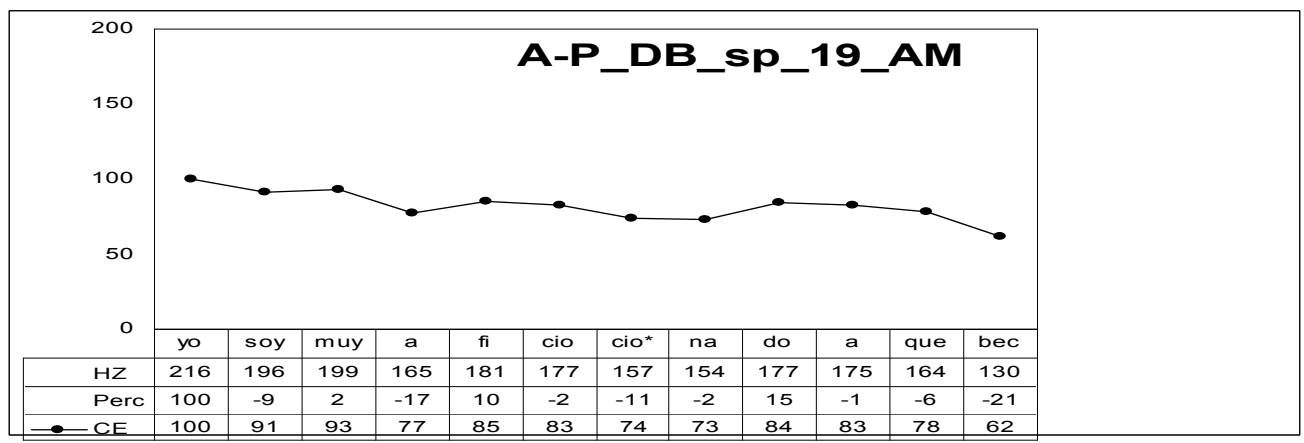

Figura 13. Corresponde a la melodía estandarizada neutra: "Yo soy muy aficionado a Quebec"

En la figura 13 observamos el mismo fenómeno. La vocal enfatizada "Que" es la átona anterior a la última tónica. Otra característica que hemos observado en los enunciados de nuestro corpus es que, en general, no hay primer pico. El primer pico indica, en español, la marca de inicio de grupo fónico (al ser la primera vocal tónica del enunciado). Nuestros informantes no lo producen. Al no haber primer pico, no hay una declinación clara a lo largo del enunciado, con lo que nos encontramos con melodías muy planas como en este enunciado.

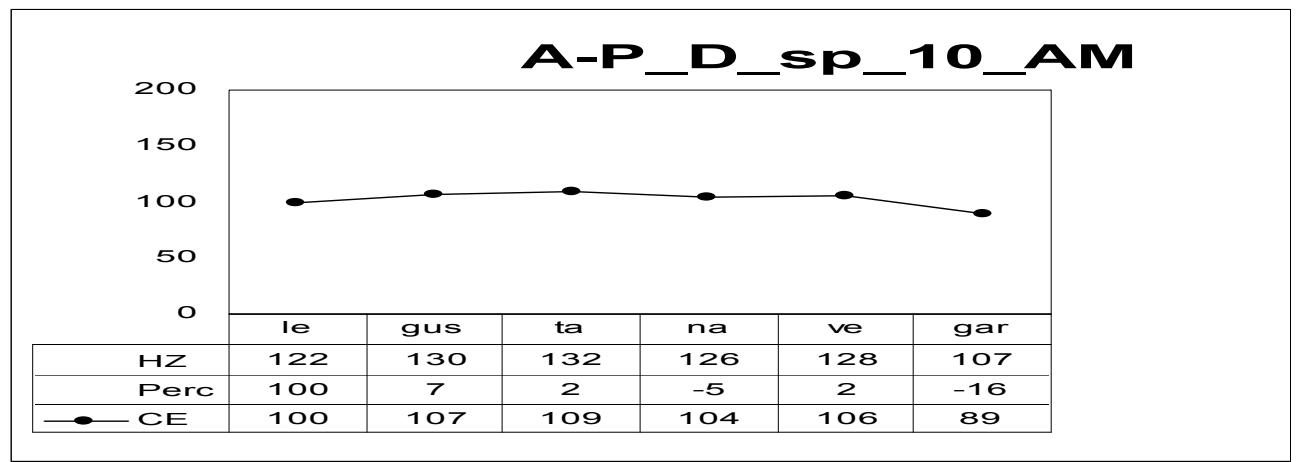

Figura 14. Corresponde a la melodía estandarizada neutra: "Le gusta navegar"

En la figura 14 observamos el mismo fenómeno. La vocal enfatizada "ve" es la átona anterior a la última tónica. Tampoco observamos primer pico con lo que el enunciado de nuevo se presenta muy plano. Este rasgo hipotizamos que es una transferencia de la L1. 


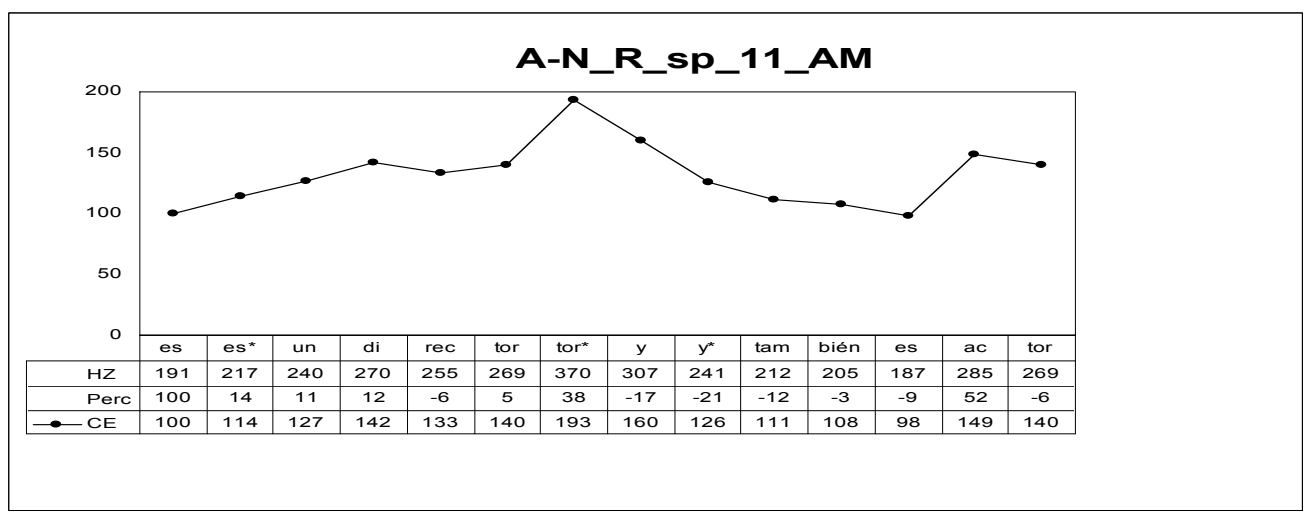

Figura 15. Corresponde a la melodía estandarizada neutra: "Es un director y también es actor"

En la figura 15 observamos un contorno interior muy ascendente en la última vocal del grupo fónico "tor", esto sucede en enunciados extensos. Es similar a los anteriores enunciados suspendidos, con un final claramente ascendente.

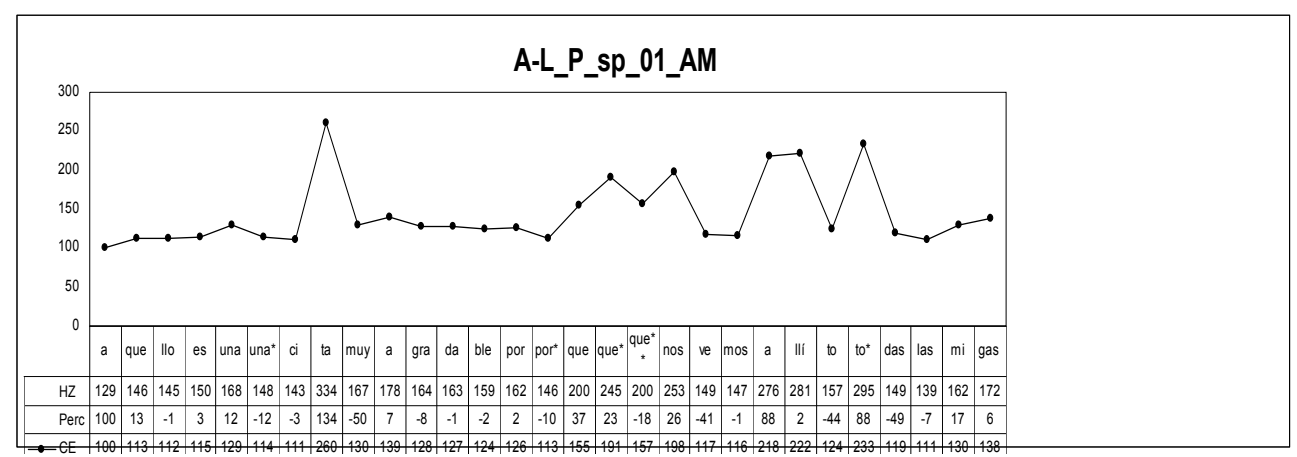

Figura 16. Corresponde a la melodía estandarizada neutra: "Aquello es una cita muy agradable porque nos vemos allí todas las amigas"

En la figura 16 observamos una serie de contornos interiores muy ascendentes con prominencias en la primera y en la última vocal del grupo fónico. Los ascensos son similares a los enunciados suspendidos. Se trata de otro rasgo de entonación prelingüística que también hipotizamos como transferencia de la L1 y es la tendencia a enfatizar la vocales átonas internas. 


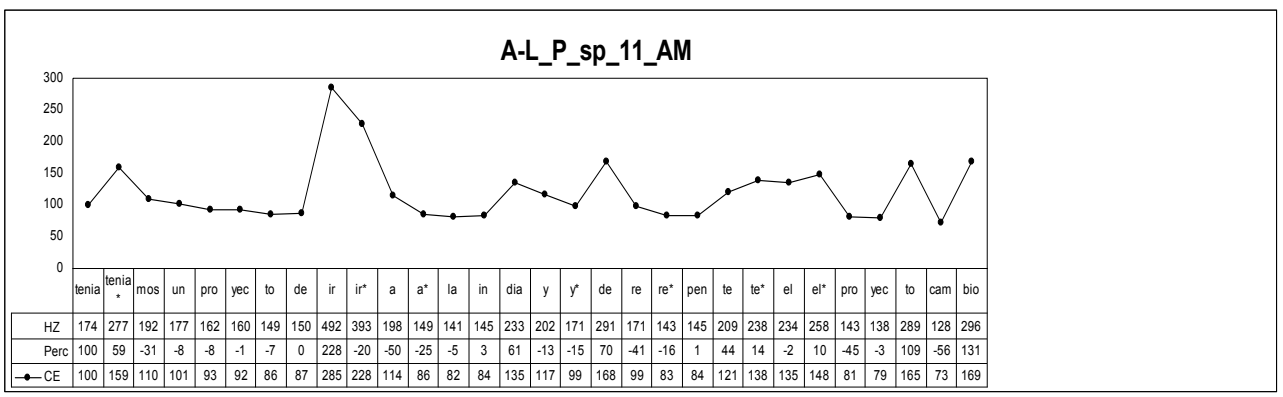

Figura 17. Corresponde a la melodía estandarizada neutra: "Teníamos un proyecto de ir a la India y de repente el proyecto cambió"

La figura 17 es otro claro ejemplo de la tendencia a producir contornos interiores muy ascendentes típicos de los enunciados suspendidos. Estos contornos interiores permiten estructurar el discurso y marcar los límites.

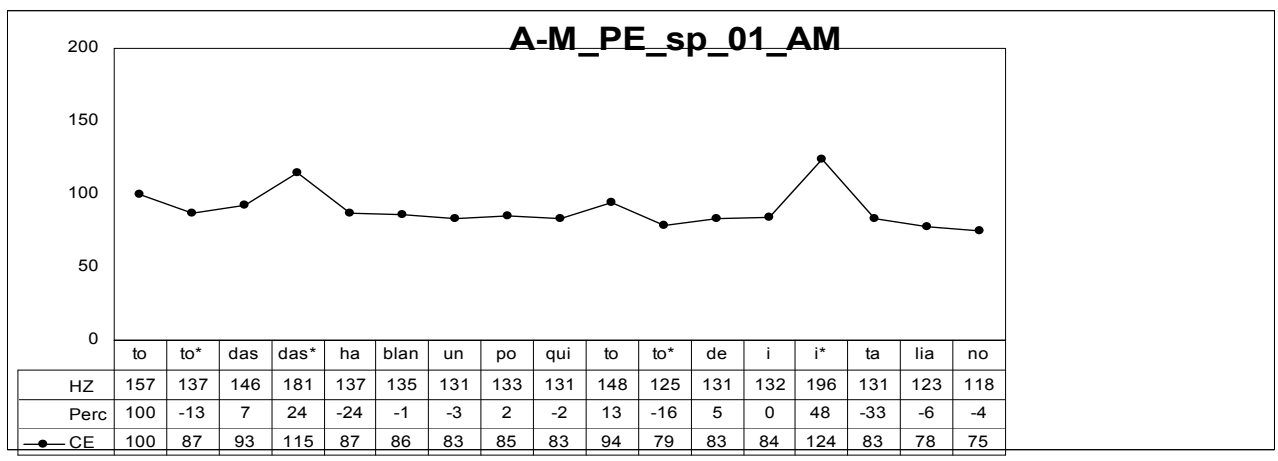

Figura 18. Corresponde a la melodía estandarizada neutra: "Todas hablan un poquito de español"

En la figura 18 observamos de nuevo la tendencia a enfatizar la vocales átonas internas. Véase la "a" de "todas" y la "o" de "poquito". En la última palabra volvemos a encontrar la característica inflexión en la pretónica "i". 


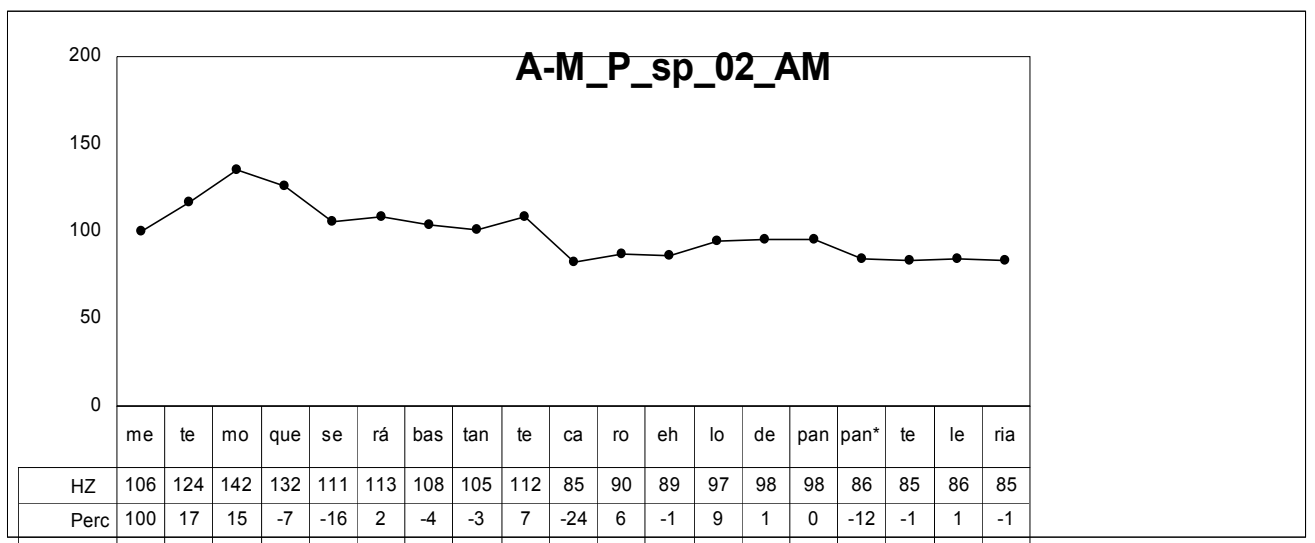

Figura 19. Corresponde a la melodía estandarizada neutra: "Me temo que será bastante caro, eh, lo de Panteleria"

En la figura 19 nos encontramos los mismos rasgos de la figura anterior: inflexiones en átonas internas "o" de "temo" y "e" de "bastante"; y, la inflexión final en pretónica "pan".

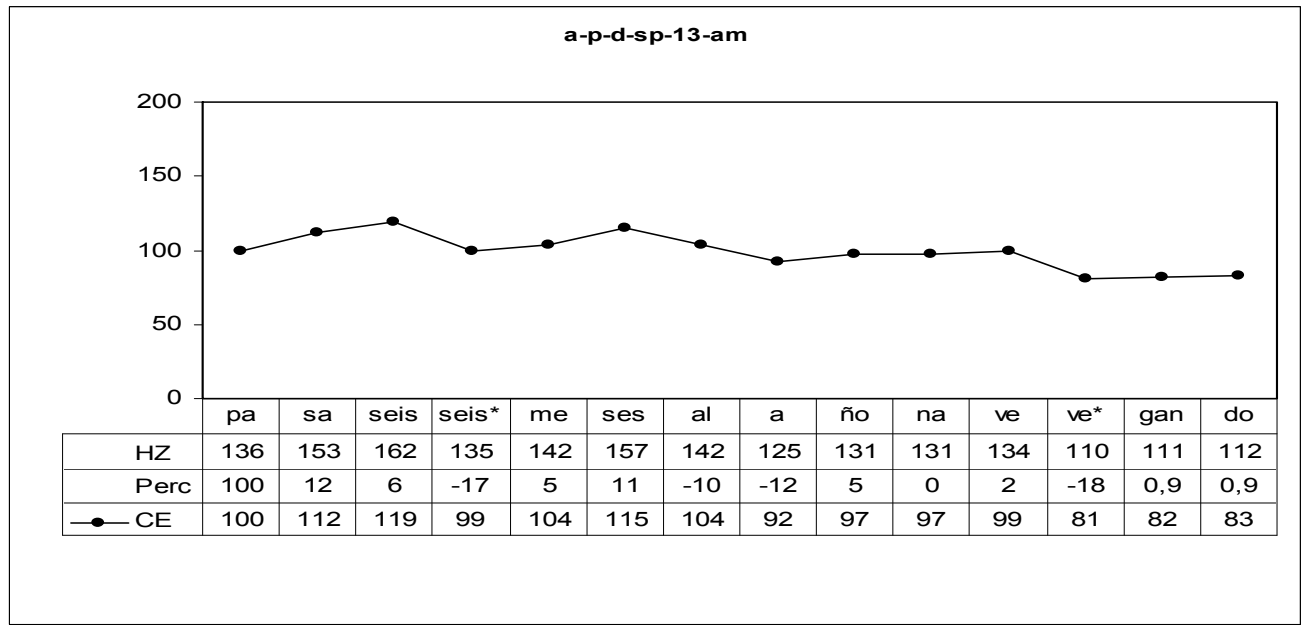

Figura 20. Corresponde a la melodía estandarizada neutra: "Pasa seis meses al año navegando"

La figura 20 es un ejemplo más de la recurrencia de los rasgos prelingüísticos identificados: inflexiones en átonas internas "e" de "meses" y la inflexión final en la pretónica "ve". 


\section{CONCLUSIONES}

Los principios teóricos en los que nos basamos para abordar el tema, el método adoptado para establecer el corpus oral, y el modelo de análisis melódico empleado para llevar a cabo este estudio, nos permiten afrontar los objetivos propuestos al inicio.

Recordamos que al comienzo de este trabajo los objetivos planteados eran los siguientes:

1) especificar la entonación lingüística de los italianos al hablar en castellano;

2) describir la entonación prelingüística de dichos informantes con un nivel avanzado de español;

3) detallar el proceso de interferencia y caracterizar la interlengua entonativa de los italianos que hablan español.

4) ofrecer una serie de propuestas didácticas para la enseñanza de la entonación en el aula.

\section{Entonación lingüistica}

Con respecto al primer objetivo hemos encontrado tres modelos de entonación neutra:

- inflexión final descendente, similar a la neutra del español

- inflexión final plana, similar a la entonación suspendida del español

- inflexión final descendente, que comienza en la última pretónica del enunciado (y no en la tónica, como en español)

Los enunciados suspendidos son sistemáticamente ascendentes, similares a las interrogativas absolutas del español.

En entonación interrogativa (un $50 \%$ de nuestro corpus) encontramos los siguientes patrones:

- inflexión final circunfleja ascendente-descendente (similar a un tipo de interrogativa en español: el patrón IV. V. Cantero \& Font, 2007)

- inflexión final circunfleja descendente-ascendente (inexistente en español como interrogativa)

- inflexión final ascendente, con un 30-40\% de ascenso (que en español sería un enunciado suspendido)

- inflexión final ascendente, con un $60-70 \%$ de ascenso (que en español tal vez podría reconocerse como interrogativa)

- inflexión final ascendente, con más de un 100\% de ascenso (como la interrogativa absoluta en español, aunque en nuestro corpus corresponde a preguntas con énfasis) 
En suma, y en cuanto a la entonación lingüística:

- los enunciados neutros con final plano no serían reconocibles en español como enunciados conclusivos, sino como suspendidos, inacabados. Como en la figura 8.

- los enunciados suspendidos, en cambio, serían reconocidos en español como interrogativos. Como en la figura 10.

- la interrogativas con final descendente-ascendente podrían ser reconocidas como enfáticas; las interrogativas con final ascendente hasta un 30-40\%, como suspendidas; las interrogativas enfáticas, en cambio, serían reconocidas como simples interrogativas, sin énfasis. Como en la figura 3.

\section{Entonación prelingüistica}

Con respecto al segundo objetivo, en general, no observamos primer pico en los enunciados de nuestro corpus. Al no haber primer pico, no hay una declinación clara a lo largo del enunciado, con lo que nos encontramos con melodías muy planas. Como en la figura 14. Por el contrario, hay una fuerte tendencia a marcar los contornos interiores, en enunciados extensos, con prominencia en la primera y en la última vocal del grupo. Estos contornos interiores permiten estructurar el discurso y marcar los límites. En español, los contornos interiores (anticadencias, en la terminología de Navarro Tomás, 1944) son melodías suspendidas, con un final levemente ascendente. En nuestro corpus, son similares a los otros enunciados suspendidos, con un final claramente ascendente. Como en la figura 15.

Otro fenómeno observable es la fuerte tendencia a enfatizar las vocales pretónicas finales y las átonas internas. Estas prominencias propias de la L1, caracterizan la interlengua de nuestros informantes y configuran el perfil melódico de la LE. Otros rasgos de ese perfil melódico serían las interrogativas con final circunflejo, el final plano de las entonaciones neutras y los contornos interiores ascendentes.

En definitiva, y en cuanto a la entonación prelingüística, la organización del discurso que observamos sería, en parte, anómala en español: sin primer pico (marca de inicio del grupo fónico), sin declinación, con contornos internos que parecen énfasis, con prominencia en átonas, con inflexiones finales que comienzan en la pretónica, con finales circunflejos característicos, etc.

Todo ello caracteriza la interlengua entonativa de los italianos que hablan español, dando respuesta al tercer objetivo que nos planteábamos, y nos ayuda a detallar el proceso de interferencia. La interlengua entonativa o perfil melódico es el eje de su "acento extranjero". Estos rasgos melódicos, descritos en la entonación lingüística y en la entonación prelingüística, que caracterizan su interlengua entonativa no impiden, en ningún caso, la comunicación con los nativos españoles, más aún, le confiere un punto de interés extra: el acento italiano es agradable al oído español. Sin embargo, las interferencias con la L1 pueden provocar malentendidos en una comunicación no meramente afectiva: un enunciado suspendido puede ser entendido por un hablante español como interrogativo, una afirmación como una frase inacabada, una pregunta como un énfasis (circunfleja descendente-ascendente) o 
como una frase inacabada, etc. Estos malentendidos también deben afrontarse en la enseñanza de la pronunciación.

Para ello ofrecemos las siguientes propuestas didácticas y llegamos al cuarto y último objetivo planteado. Siendo conscientes de que no podemos prescindir de la entonación en ningún acto comunicativo debemos tenerla en cuenta a lo largo de todo el diseño curricular: en los objetivos, en el sílabo, en las actividades, en la evaluación, etc.

Según Cortés Moreno (2002), el primer paso para la elaboración del sílabo prosódico es la comparación entre la lengua de los alumnos y el español en lo referente a acentuación y entonación. Un análisis contrastivo, como el que el autor propone, permite detectar los aspectos problemáticos en potencia, mientras que un estudio de la interlengua como el realizado en esta investigación permite, además, captar los rasgos de L1 que quedan más fosilizados en la L2 a un nivel avanzado y así conocer cuáles son los fenómenos que deben ser trabajados con mayor atención. Algunos autores han diseñado interesantes actividades que se podrían adaptar a la enseñanza de la entonación del español a italianos, para ello mostramos algunos ejemplos basándonos en los resultados de esta investigación:

a) Según Giovanni et al. (1996: 87), el alumno escucha un enunciado, observa unas opciones escritas y escoge la que corresponde al enunciado que ha oído. Este ejercicio se podría adaptar mostrando a los alumnos los gráficos con la curva estandarizada que hemos presentado y pidiéndoles que escojan cuál enunciado de audio es el correspondiente. Se podría presentar un solo gráfico con su transcripción ortográfica y manipular el archivo audio con los valores del español convirtiendo, por ejemplo, la neutra en interrogativa y en suspensa Tendrían así tres archivos audio para un solo gráfico.

b) Artuñedo \& Donson (1995:10) proponen hablar acompañando la producción oral de movimientos de la mano: ésta sube o baja según el tono de la voz. Este ejercicio serviría para trabajar tanto los rasgos de entonación lingüística como los rasgos de entonación prelingüística.

c) Celce-Murcia et al. (1987: 151) proponen escuchar un diálogo y colocar los signos de puntuación pertinentes. Este ejercicio serviría únicamente para trabajar la entonación lingüística y se presentaría en vez de un diálogo los enunciados del corpus español hablado por españoles.

d) Bourdages et al. (1987: 151) proponen escuchar unos enunciados y observar las trascripciones entonativas respectivas. En este caso se presentarían los gráficos y se señalarían con un círculo los rasgos significativos para que los alumnos pudieran reconocerlos mejor. Se podría coger gráficos del corpus de español hablado por españoles y del corpus de español hablado por italianos para que pudieran comparar las diferencias y las interferencias más comunes.

e) Cortés Moreno (2002) propone un ejercicio en el que de una película seleccionamos enunciados con una clara carga expresiva (p. ej., sarcasmo, 
alegría, depresión, cólera, etc.), los grabamos en una casete de audio y suprimimos el componente visual. Los alumnos escuchan la casete e interpretan la actitud que les sugiere el enunciado. En nuestro caso se podrían mostrar también enunciados del español hablado por italianos y enunciados del español hablado por españoles y preguntar a los alumnos italianos, a partir de la comparación, qué rasgos de la interlengua de los italianos consideran que no son propios del español.

Estos son algunos ejemplos de cómo trabajar la entonación y de cómo ayudar a evitar los malentendidos a los que nos referiamos con antelación, ciertamente podrían haber muchos más, sólo es cuestión de proponérselo y ponerle un poco de imaginación. La evaluación debería, por otra parte, utilizar el mismo tipo de actividades empleadas en la enseñanza. De esta manera los alumnos se sentirían más familiarizados y observarían que las actividades de clase tienen una utilidad y un sentido. En cualquier caso, y como bien apunta Cortés Moreno (2002) "un dominio auténtico de la entonación sólo se logra a base de dialogar con otros interlocutores". Estos ejercicios son útiles pero no pueden sustituir la conversación directa con los hablantes de la lengua que se está estudiando. Es en la comunicación real, la de la calle, la verdadera donde perfeccionamos, pero no perfeccionamos porque queremos perfeccionar sino porque queremos sentirnos cercanos a nuestros interlocutores. El motor de la comunicación es la relación social afectiva por eso no aprenderemos con todos sino sólo con aquellos que nos interesen porque sentimos una unión afectiva con ellos. En clase es necesario mostrar las características físicas de la lengua, los ejercicios son útiles para superar obstáculos pero como profesores de lengua no podremos olvidar que lo más importante es enseñar como funciona la comunicación, su complejidad, su esencia.

\section{REFERENCIAS BIBLIOGRÁFICAS}

ARTUÑEDO, B. \& C. DONSON (1995): Ele 2: curso de español para extranjeros (libro del profesor), Madrid, SM.

BOERMAS, P. \& D. Weenink (1992-2010): PRAAT. Doing Phonetics by Computer. Institute of Phonetic Sciences. University of Amsterdam. Disponible en Web: http://www.praat.org. [Consulta: 03 de septiembre de 2010].

BOURDAGES, J. et al. (1987): “Approche intégrée pour l'enseignement de la phonétique", The Canadian Modern Language Review, 146-158.

CANTERO SERENA, F. J. (2002): Teoría y análisis de la entonación. Barcelona, Edicions de la Universitat de Barcelona.

CANTERO SERENA, F. J. (2008): "Complejidad y competencia comunicativa". Revista Horizontes de Lingüistica Aplicada, Ano 7 - N 1 (Brasilia). Disponible en Web: http://www.revistahorizontes.unb.br/ [Consulta: 03 de septiembre de 2010]. 
CANTERO SERENA, F.J. \& D. Font Rotchés (2007): "Entonación del español Peninsular en habla espontánea: patrones melódicos y márgenes de dispersión", Moenia, 13, 69-92.

CANTERO SERENA, F.J. \& D. Font Rotchés (2009): "Protocolo para el análisis melódico del habla", Estudios de fonética Experimental, XVIII. Disponible en Web: http://www.ub.edu/labfon/XVIII-06.pdf [Consulta: 03 de septiembre de 2010].

CELCE-MURCIA, M. et al. (1996): Teaching Pronunciation: A reference for teachers of English to speakers of other languages, Nueva York, C.U.P.

CORTÉS MORENO, M. (2002). "Didáctica de la entonación: una asignatura pendiente", Didáctica (Lengua y Literatura), Universidad Complutense de Madrid, 14, pp. 65-75.

DEVÍS HERRAIZ, E. (2008): La prosodia nell'interferenza tra L1 e L2: due varietà di italiano e spagnolo a confronto. Università Degli Studi di Pisa. Disponible en Web: http://etd.adm.unipi.it/theses/available/etd-04222008-180251/ [Consulta: 03 de septiembre de 2010].

FONT ROTCHÉS, D. (2007): L'entonació del català. Barcelona, Publicacions de l'A badia de Montserrat, Biblioteca Milà i Fontanals, 53.

GIOVANNINI, A. et al. (1996): Profesor en acción (2), Madrid, Edelsa.

NAVARRO TOMÁS, T. (1944): Manual de entonación española, New York, Hispanic Society. (1974) Madrid, Guadarrama.

QUILIS, A. (1993): Tratado de fonología y fonética españolas, Madrid, Gredos.

SELINKER, L. (1972): "Interlanguage", International Review of Applied Linguistics, $10,209-241$. 


\section{APÉNDICE 1}

\begin{tabular}{|c|c|}
\hline Código & Transcripción ortográfica \\
\hline 1. A-I.S sp 01 AM & Me parece que sí \\
\hline 2. I-I S sp 01 AM & ¿Si estás de acuerdo? \\
\hline 3. A-M.P_sp_01_AM & Tiene que ser una semana ya te lo digo \\
\hline 4. A-M.P_sp_02_AM & $\begin{array}{l}\text { Me temo que será bastante caro, eh, lo } \\
\text { de Panteleria }\end{array}$ \\
\hline 5. A-M.P_sp_03_AM & Son barcos muy caros, muy sucios \\
\hline 6. A-M.PE sp 01 AM & Todas hablan un poquito de italiano \\
\hline 7. A-M.PE_sp_02_AM & Lo llevan todo un poco retrasado \\
\hline 8. A-L.A_sp_01_AM & Es italiano y vive en Venecia \\
\hline 9. A-L.A_sp_02_AM & Cambia de personalidad \\
\hline 10. A-L.A_sp_03_AM & $\begin{array}{l}\text { Vamos a programarnos un viaje yo y } \\
\text { Gloria con nuestros amigos }\end{array}$ \\
\hline 11. A-L.A_sp_04_AM & Vive aun \\
\hline 12. A-L.A_sp_06_AM & Yo ya he decidido \\
\hline 13. I-L_A_sp_01_AM & ¿Aun está vivo? \\
\hline 14. I-L_A_sp_02_AM & ¿Es calvo? \\
\hline 15. I-L_A_sp_03_AM & ¿Es español? \\
\hline 16. I-L_A_sp_05_AM & ¿Es un artista? \\
\hline 17. I-L_A_sp_07_AM & ¿Está vivo aun? \\
\hline 18. I-L_A_sp_08_AM & ¿Hace teatro? \\
\hline 19. I-L_A_sp_10_AM & ¿Pertenece a un movimiento político? \\
\hline 20. I-L_A_sp_11_AM & ¿Sale por la radio? \\
\hline 21. A-L_P_sp_01_AM & $\begin{array}{l}\text { Aquello es una cita muy agradable } \\
\text { porque nos vemos allí todas las amigas }\end{array}$ \\
\hline 22. A-L_P_sp_04_AM & $\begin{array}{l}\text { Fue bastante divertido dentro de lo que } \\
\text { cabe, de lo que cabe }\end{array}$ \\
\hline 23. A-L_P_sp_05_AM $0 \mathrm{~mm}$ & $\begin{array}{l}\text { Íbamos notando progresos de la niña, } \\
\text { que si un día decía una cosa, que si un } \\
\text { día decía otra }\end{array}$ \\
\hline 24. A-L_P_sp_06_AM & Murió junto con otro \\
\hline 25. A-L_P_sp_09_AM & $\begin{array}{l}\text { Pero llevándome cosas para trabajar en } \\
\text { el Vaporetto }\end{array}$ \\
\hline 26. A-L_P_sp_11_AM & $\begin{array}{l}\text { Teníamos un proyecto de ir a la India } \\
\text { y de repente el proyecto cambió }\end{array}$ \\
\hline 27. I-L_P_sp_01_AM & ¿Cantante? \\
\hline 28. I-L_P_sp_02_AM & ¿Cantante lírico? \\
\hline 29. I-L_P_sp_06_AM & ¿Es un literato? \\
\hline
\end{tabular}




\begin{tabular}{|c|c|}
\hline 30. I-L_P_sp_07_AM & ¿Música clásica? \\
\hline 31. I-L_P_sp_08_AM & ¿Música folk? \\
\hline 32. I-L_P_sp_09_AM & ¿Tiene ese nombre impronunciable? \\
\hline 33. I-L_P_sp_10_AM & ¿Una presentadora? \\
\hline 34. I-L_P_sp_11_AM & ¿Vive en Barcelona? \\
\hline 35. A-P_DB_sp_07_AM & $\begin{array}{l}\text { Fui de vacaciones en Quebec que me } \\
\text { ha gustado muchísimo }\end{array}$ \\
\hline 36. A-P_DB_sp_08_AM & $\begin{array}{l}\text { Hay italianos que pones sus } \\
\text { comentarios de las pelis en italiano }\end{array}$ \\
\hline 37. A-P_DB_sp_15_AM & $\begin{array}{l}\text { Primer periodo en ocho años que estoy } \\
\text { haciendo un trabajo solo }\end{array}$ \\
\hline 38. A-P_DB_sp_19_AM & Yo soy muy aficionado a Quebec \\
\hline 39. A-P_DB_sp_22_AM & $\begin{array}{l}\text { Yo tengo una amiga que tiene una casa } \\
\text { en Lerici }\end{array}$ \\
\hline 40. I-P_DB_sp_01_AM & ¿Esta peli la conoces tú? \\
\hline 41. I-P_DB_sp_02_AM & ¿Yo solamente puedo decir sí o no? \\
\hline 42. A-PA_S_sp_04_AM & $\begin{array}{l}\text { Aquí hablamos normalmente en } \\
\text { español }\end{array}$ \\
\hline 43. A-PA_S_sp_14_AM & Lo lleva corto \\
\hline 44. A-PA_S_sp_19_AM & $\begin{array}{l}\text { Nosotros de hecho podríamos hacerlo } \\
\text { porque mi mujer sí que sabe hablar en } \\
\text { italiano }\end{array}$ \\
\hline 45. A-PA_S_sp_20_AM & Parece una escena de Goya \\
\hline 46. A-PA_S_sp_25_AM & Tiene tres idiomas como base \\
\hline 47. I-PA_S_sp_01_AM & ¿Es también una película? \\
\hline 48. I-PA_S_sp_07_AM & $\begin{array}{l}\text { ¿Es una película en general de } \\
\text { Latinoamérica? }\end{array}$ \\
\hline 49. I-PA_S_sp_08_AM & ¿Es una película europea? \\
\hline 50. I-PA_S_sp_13_AM & ¿Lleva bigote? \\
\hline 51. I-PA_S_sp_15_AM & ¿Esa otra de Bigas Luna la has visto? \\
\hline 52. A-P_D_sp_03_AM & Cambiamos cada vez de islas, eh \\
\hline 53. A-P_D_sp_09_AM & Es un ex tenista \\
\hline 54. A-P_D_sp_10_AM & Le gusta navegar \\
\hline 55. A-P_D_sp_11_AM & Mitad de la semana que viene \\
\hline 56. A-P_D_sp_13_AM & Pasa seis meses al año navegando \\
\hline 57. I-P_D_sp_02_AM & ¿Cambia de personalidad? \\
\hline 58. I-P_D_sp_10_AM & ¿Es alemán? \\
\hline 59. I-P_D_sp_11_AM & ¿Es americano? \\
\hline 60. I-P_D_sp_29_AM & ¿Pero tú puedes sólo por las tardes? \\
\hline 61. I-P_D_sp_34_AM & ¿Tú tienes hijos? \\
\hline
\end{tabular}




\begin{tabular}{|c|c|}
\hline 62. A-A_P_sp_01_AM & $\begin{array}{l}\text { Yo tengo ya julio ya ocupado porque } \\
\text { tengo que trabajar }\end{array}$ \\
\hline 63. A-A_P_sp_02_AM & $\begin{array}{l}\text { Me gustaría algo de tranquilo, no sé si, } \\
\text { si un turismo rural }\end{array}$ \\
\hline 64. I-A P sp 02 AM & ¿Es rico? \\
\hline 65. I-A_P_sp_03_AM & ¿Un actor? \\
\hline 66. I-A_P_sp_05_AM & ¿Habla inglés? \\
\hline 67. I-A_P_sp_06_AM & ¿La ciudad es europea? \\
\hline 68. I-A_P_sp_13_AM & ¿Es italiano? \\
\hline 69. A-A_I_sp_06_AM & $\begin{array}{l}\text { La idea es traducir, o mejor, subtitular, } \\
\text { los programas al catalán }\end{array}$ \\
\hline 70. A-A_I_sp_09_AM & No es propiamente político \\
\hline 71. A-A_I_sp_11_AM & $\begin{array}{l}\text { No es un mismo informativo traducido } \\
\text { en veintiún idiomas, son ventiún } \\
\text { informativos independientes cada uno } \\
\text { en su idioma }\end{array}$ \\
\hline 72. A-A_I_sp_13_AM & $\begin{array}{l}\text { Sí que se considera público todos los } \\
\text { catalanes, o todas las personas que } \\
\text { entienden el catalán en Barcelona }\end{array}$ \\
\hline 73. A-A_I_sp_16_AM & $\begin{array}{l}\text { Uno de los colectivos más nombrosos } \\
\text { europeos, el más nombroso, son los } \\
\text { italianos }\end{array}$ \\
\hline 74. I-A_I_sp_01_AM & ¿Catalán? \\
\hline 75. I-A_I_sp_02_AM & ¿Cocinero? \\
\hline 76. I-A_I_sp_03_AM & ¿Comodín público? \\
\hline 77. I-A_I_sp_08_AM & ¿Político? \\
\hline 78. I-A_I_sp_09_AM & ¿Puede ser un lugar? \\
\hline 79. A-M_B_sp_03_AM & Allí me matriculé \\
\hline 80. A-M_B_sp_18_AM & $\begin{array}{l}\text { La perspectiva que te dan es enseñanza } \\
\text { secundaría, no, y a mi francamente no } \\
\text { me atrae nada }\end{array}$ \\
\hline 81. A-M_B_sp_22_AM & $\begin{array}{l}\text { Pensaba no sé más la traducción o } \\
\text { otras cosas, pero la enseñanza no }\end{array}$ \\
\hline 82. A-M B sp 37 AM & Y después yo quería ir al Brasil \\
\hline 83. A-M_B_sp_44_AM & $\begin{array}{l}\text { Yo llegué en el noventa y uno y vine } \\
\text { con una beca erasmus }\end{array}$ \\
\hline 84. I-M_B_sp_01_AM & ¿Aparece en la peli? \\
\hline 85. I-M_B_sp_02_AM & ¿El director es famoso? \\
\hline 86. I-M_B_sp_05_AM & ¿Es italiano? \\
\hline 87. I-M_B_sp_07_AM & ¿Es muy alto? \\
\hline
\end{tabular}




\begin{tabular}{|l|l|}
\hline 88. I-M_B_sp_21_AM & ¿Puedo empezar ya? \\
\hline 89. A-N_R_sp_01_AM & A mi me sorprendió \\
\hline 90. A-N_R_sp_07_AM & En el Verdi hacen buenas películas \\
\hline 91. A-N_R_sp_11_AM & Es un director y también es actor \\
\hline 92. A-N_R_sp_20_AM & $\begin{array}{l}\text { Francamente me sorprendió } \\
\text { muchísimo }\end{array}$ \\
\hline 93. A-N_R_sp_28_AM & Probablemente sea verdad \\
\hline 95. I-N_R_sp_01_AM & ¿De ópera? \\
\hline 96. I-N_R_sp_03_AM & ¿Otra película? \\
\hline 97. I-N_R_sp_06_AM & ¿Músico? \\
\hline 98. I-N_R_sp_07_AM & ¿Un político? \\
\hline 99. I-N_R_sp_10_AM & ¿Qué es el balañá? \\
\hline
\end{tabular}

